Pharmacopœia, it is, as far as my information extends, little used by practitioners at present. Yet in cases of habitual constipation it should be preferred to most other cathartics, as it operates without occasioning heat or irritation, and leaves the bowels in a good state. Its superiority in removing or relievinir obstinate constipation has recently been tested in this vicinity. The patient $I$ allude to is a female, who has been confined to her bed for more than a twelve month with chronic inflanmation of the pelvic viscera and obstinate constipation. Most of the powerful cathartics, in conjunction with other medicines, were used, none of them producing evacuations without the assistance of enemas, with the exception of croton oil, which relieved for a few times and then seemed to lose its effect. Through the advice of a young member of the profession, the extract of butternut was used in full doses, and repeated. In the first instance sickness and vomiting followed, but the bowels soon moved freely. The decoction or extract has since been sufficient to keep the bowels in a soluble state, without the assistance of enemas. Conjoined with calomel, it is especially efficacious in bilious habits. If griping is produced, carininatives and corrigents are used with effect.

Great Barrington, Mass., Dec. 27, $1837 . \quad$ N. B. Pickett.

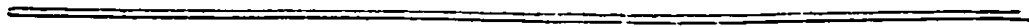

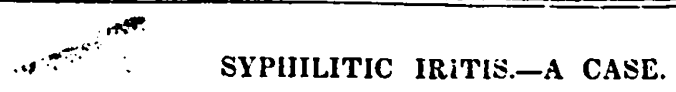

BT EDWARD J. DAVENPORT, M.D., BOSTON.

[Communicated for the Boston Medical and Surg̣ical Journal.]

InfaAmmation of the iris does not often occur uncombined with disease of-some other texture of the eye. In recent cases, there is frequently; conjunctivitis; in long-continued or neglected iritis there will almost invariably be associated with it, inflammation of some of the deepseated textures. This is believed to occur more particularly in syphilitic iritis-hence 'the title of syphilitic or "venereal ophthalmia," applied by some authors to these cases." "But when a case of iritis is presented for treatment, it is not always an "easy matter to decide whether it be of syphilitic; or of rheunatic, or atmospheric origin, unless the practitioner is acquainted with its previous "history ; and this may be intentionally withheld by the patient. "Saunders, in his valuable treatise on the diseases of the eye, gives the "following differential symptoms between syphilitic and simple inflamniation of the iris. "In syphilitic iritis," he says, "the iris is "much'"'more thickened and puckered, the texture appears more changed, the irritation on exposure to light is less, the pain is most intense at "nightit' red vessels are seen in the substance of the iris-a circumstance not: often seen in the early stage of simple iritis, in which, patients, from "the severity of the pain, are sooner induced to apply for relief-the:püpil is not so much contracted as in the simple inflamniation; and aliborugh the general appearance of disease be greater, the pain is actually less and the blindness is often total: to which, perhaps, may be addêt, that the lymph is deposited, as it were, in drops, and assumes a tubicícular appearance." P. 64. Fortunately, 
bowever, it is not absolutely essential in the treatment of iritis to know whether it be of syphilitic origin or not ; for in every well-marked case, it is proper to administer mercury in some form, to insure a speedy and permanent cure. Nevertheless, cases do occur in which the treatment usually employed in inflammation of other textures of the eye, will be sufficient; also in another class, from idiosyncrasy or some other cause, mercury may be inadnissible, and recourse must be had to active remedies of a different character. In the following case, mercury was administered with the most decided benefit.

B. A., house carpenter, 23 years of age, applied in the month of February, with an inflammation of the iris in the right eye, of eight or nine days' standing. He stated that a few weeks previous to the present application, he had made pretty free use of the strong mercurial ointment for the cure of pediculi of the scrotum. Soon after this he was attacked with a rheumatic affection of the limbs, for which he was treated at the Massachusetts General Hospital, with relief. Upon leaving the hospital, he exposed himself abroad on a cold and wet day, and immediately upon his return home he felt some uneasiness in the eye, which soon amounted to positive inflammation.

Upon examination, the inflamed vessels of the eye appeared of a mixed characier; the superficial network of vessels belonging to the conjunctiva being considerably injected, and the same time the sclerotic vessels forming the ciliary zone around the cornea being very distinct. The conjunctiva of the lids was not much inflamed. The iris-naturally blue-had changed to a green color, and was limited and sluggish in its motions ; the pupil was quite hazy, somewhat contracted, and irregular, with the pupillary margin of the iris retracted towaids the crystalline lens. Upon this margin, towards the external canthus, was seen a yellowish-colored tubercle of lymph, of a small size; intolerance of light and epiphora inconsiderable ; slight haziness of the entire cornea ; pain occurring in paroxysms, referred to the eyeball and occasionally to the brow ; vision so much impaired that he could not distinguish any object at all ; and this circumstance, as usually happens, created much alarm, and chiefly induced him to apply for advice. In this case there was so little constitutional disturbance, that the patient was very unwilling to confine himself to the house, or to refrain from taking the same food he was accustomed to when in health.

Wednesday. One eye only being affected, he was cupped upon the right temple to the amount of ten or twelve ounces, and was directed to take an active cathartic, to have anodyne fomentations to the eye, and to keep in a dark apartment.

Thursday. Patient remains much the same. Six ounces of blood were taken from the temple; he was directed to repeat the catbartic, and to take at bed time a pill of calomel and opium.

Friday. The inflammation, apparently, was not much diminished, but the pulse and general strength were considerably reduced. Directed calomel and opium in full doses, morning, noon, and night. In less than a week his gums became tender, and a most marked amendinent immediately took place. The inflammation rapidly diminished, the deposit 
of lymph upon the iris disappeared, and vision improved daily. As the haziness of the cornea went off, very minute and dark-colored specks appeared upon that membrane for some time after the subsidence of the other symptoms. The extract of stramonium having been applied, after the gums had becone tender, the pupil was fully dilated, and presented a margin of extreme irregularity, with extensive adhesions between the iris and the capsule of the lens. There were also bands of lymph of a brownish color extending across the pupil. Notwithstanding which, vision was rendered much clearer by the action of the extract. The gums were kept tender with moderate doses of calomel, for three or four weeks, the application of stramonium being continued meanwhile night and morning, until there was no longer any danger of adhesions taking place. In the course of a month or six weeks, he was able to return to his work. Four months afterwards, the case was again seen, and not a trace of the former disease could be discovered. Power of vision was equally good in each eye.

No. 4 Winter Street, Jan., 1838.

\section{CANNA COCCINEA.}

To the Editor of the Boston Medical and Surgical Journal.

Dear Sir,-By the present opportunity 1 send you a small quantity of a new nutritious aliment, which has lately been sent me by a friend in the island of St. Christopher, West Indies, and which appears to be a very valuable acquisition to the list of our nutritions articles for the sick and convalescent.

This article is the product of the canna coccinea, somershat resembling arrow root, but is found, by analyzing it, to be quite different from the latter. In the language of a physician in the island- "I consider it, as a diet for the sick, very far superior to sago, tapioca, arrow root, and gruel. My own experience makes me satisfied that it is a most nutritious diet, easily digestible, and is consequently invaluable in diet for infants and children, and is eminently adapted for persons of dysenteric, diarrhœal, and consumptive habits, because there is, in my opinion, less acid in it than in any other farinaceous food with which $I$ an acquainted. I have never known it turn sour on the stomach. It is the ordinary food of the dyspeptic, and in enemas it is truly serviceable for allaying the effects of acrid bile on the coats of the rectum, and for sheathing them in cases of abrasion and inflammation."

Dr. Ryan, of London, in his Journal, speaking of the canna coccinea, says, "It makes a more consistent and delicious jelly than arrow root, and is, in my opinion, far superior to it or any other farinaceous powder used in this country, as an aliment for infants, invalids, or convalescents. It is prepared like arrow root, and about half the quantity makes a thicker jelly. It deserves the high praise bestowed upon it by Dr. Waterson, and cannot fail to be patronized by the medical profession and the public."

This substance is obtained from the roots of the canna coccinea when 